\title{
Implementing Wait Time Innovation in Election Administration: The Case of the EVWait Times App
}

\section{Tim Tsujii}

\begin{abstract}
This case study looks into the evolution of a web-based tool for tracking wait times during an election. Drawing inspiration from the wait time tracking system at Walt Disney World, the Forsyth County Board of Elections implemented a wait time tracking application, called EVWait Times, for early voting in the 2016 general election. Using an ESRI (ArcGIS software platform) tool, the free web app provided ( 1 ) hours and location of early voting sites, $(2)$ the wait times at the early voting sites, (3) information on finding the closest voting site, and (4) driving directions to the sites, which were all posted on a map display on the Forsyth County Board of Elections website. While the wait time tracking tool is primarily intended for quickly disseminating wait time information to voters, the secondary benefit is to use the information that was collected during this time to analyze the early voting traffic and determine which sites received more early voters than others. This information will allow our staff to make any improvements for future elections to better manage the voter turnout at the early voting sites.
\end{abstract}

T. Tsujii $(\bowtie)$

Forsyth County Board of Elections, Winston-Salem, NC, USA

e-mail: tsujiidt@forsyth.cc

(C) The Author(s) 2019

M. Brown et al. (eds.), The Future of Election Administration, Elections, Voting, Technology, https://doi.org/10.1007/978-3-030-18541-1_22 
Keywords Wait times $\bullet$ Long lines $\bullet$ Technology $\bullet$ Automation

- Web app and early voting

My professional career in election administration began in 2005 as the Early Voting Director for the Guilford County (NC) Board of Elections; I was later promoted to Deputy Director of Elections. In 2016, I was appointed as the Director of Elections to the Forsyth County Board of Elections. Forsyth County (Winston-Salem) is North Carolina's 4th largest county, with 101 precincts and serving approximately 250,000 registered voters. I've spent 14 years in elections and I've loved every minute of it -no two elections are alike. It is a thrill for me to serve the voters of my county.

We have a slogan in our office, "Voter Service > Customer Service." As part of that mantra we are always looking for technological improvements so that we can provide greater voter service. Automation is an integral part that can make the elections process more effective and efficient. The combination of technology and human processes is a melding of two pieces that can make the process work better and also helps eliminate human error. The early voting wait time tracking application, or EVWait Times, is an illustration of how that combination can work in a local election office.

\section{Early Voting Wait Time Tracking App}

I drew inspiration for the wait time tracking app from a family trip to Walt Disney World back in 2014. They have wait time monitors at the entrances to every attraction and you can also track the wait times on the Disney World app through any mobile device. I recall as we entered the queue for the Snow White and the Seven Dwarfs Mine Train ride, a Disney cast member handed me a red RF-activated (radio frequency) card to hold on to in the queue. When each guest gets through the line to the turnstile, they hand this card back to the Disney cast member who then scans the card to calculate the wait time for that guest and updates the monitors and the Disney World app. The cast members repeat this process throughout the day as guests go through the lines of the various attractions at the theme park.

As I was standing in line I started thinking about the card and wondered how we could apply this concept to election lines and the wait times at polling places. Previously, we would have to take a slip of paper, write 
the start time on it, hand it to the voter in the back of the line, instruct them to give the slip of paper to the poll worker at the registration table, record the end time, and call it in to the elections office. I wanted to find a way to track and disseminate the wait times in a more efficient manner that was paperless, digital, automated, calculator-free, and simple, just like the model used in Disney World.

When I returned home, I began researching tools that already existed and I found a mobile timesheet app that applied the same principles as the Disney tool. It was free, and so I downloaded it onto iPads and we created red cards similar to what they hand out at Disney World, and piloted it. The pilot went well, but we decided there were ways to improve on the process.

In Forsyth County, the 2016 general election was projected to have high-volume voter turnout for early voting. The Forsyth County Board of Elections wanted to be able to provide information to the public in regard to early voting sites along with wait times. In collaboration with the county information technology department and geographic information office, we developed the EVWait Times application using an ESRI (ArcGIS software platform) web-based tool to provide the following information: (1) hours and location of early voting sites, $(2)$ the wait times at the early voting sites, (3) the closest voting site, and (4) driving directions to the sites.

One reason the EVWait Times application works so well is because of its simplicity. Poll workers hand out a lanyard with an instruction card (Fig. 22.1) to the voter at the end of the line. Then the poll workers press a Start/Stop button on a tablet device. The voter returns the lanyard to a poll worker when they arrive at a registration table and the Start/Stop button is pressed to stop the timer. The process is repeated continuously throughout the day to update the wait times. This Start/ Stop (Figs. 22.2 and 22.3) website is linked to an SQL server. The times captured in the SQL server database are linked directly to the EVWait Times via a Web View; so as times are updated the application is also updated in real time.

Figure 22.4 is a screenshot from EVWait Times. The map shows the locations of the early voting sites along with the wait time. The wait time is represented by graduated circles using a gradient color scheme. This allows individuals using the application to quickly identify locations with shorter wait times (small green circles) versus the longer wait times (larger red circles). 


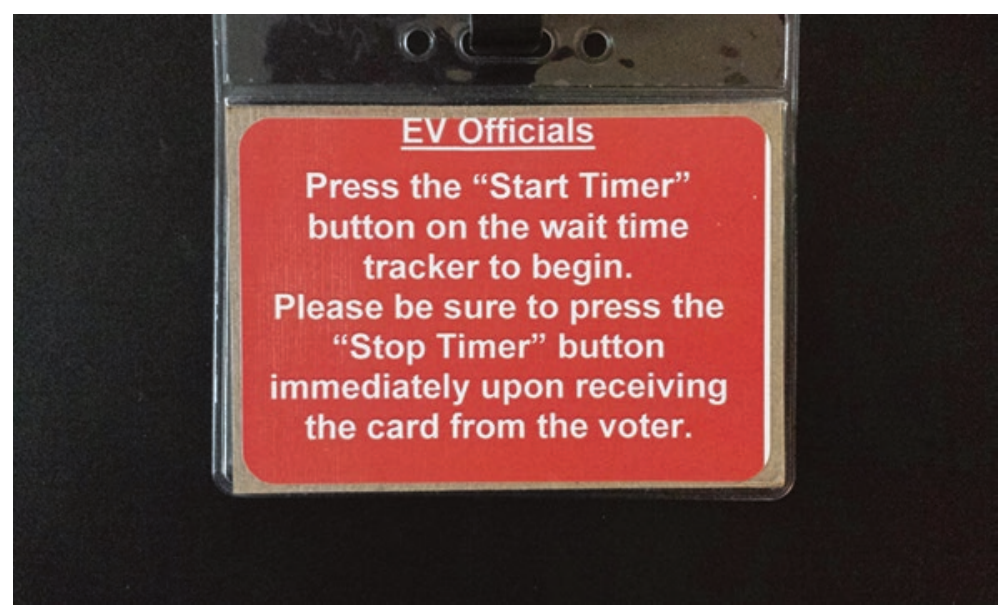

Fig. 22.1 Lanyard with instructions

Fig. 22.2 Start button

\section{Board of Elections}

Wait Timer

Start Timer

Fig. 22.3 Stop button

Board of Elections

Wait Timer

Stop Timer

Once an individual finds a site he/she might be interested in they can tap on the circle and an information window opens (Fig. 22.5), giving them more information about the voting site such as hours of operations, address, and the exact wait time.

EVWait also provides individuals a way to get driving directions to the voting site they have chosen (Fig. 22.6). The driving directions are stepby-step directions with an estimated arrival time, similar to Google Maps. 


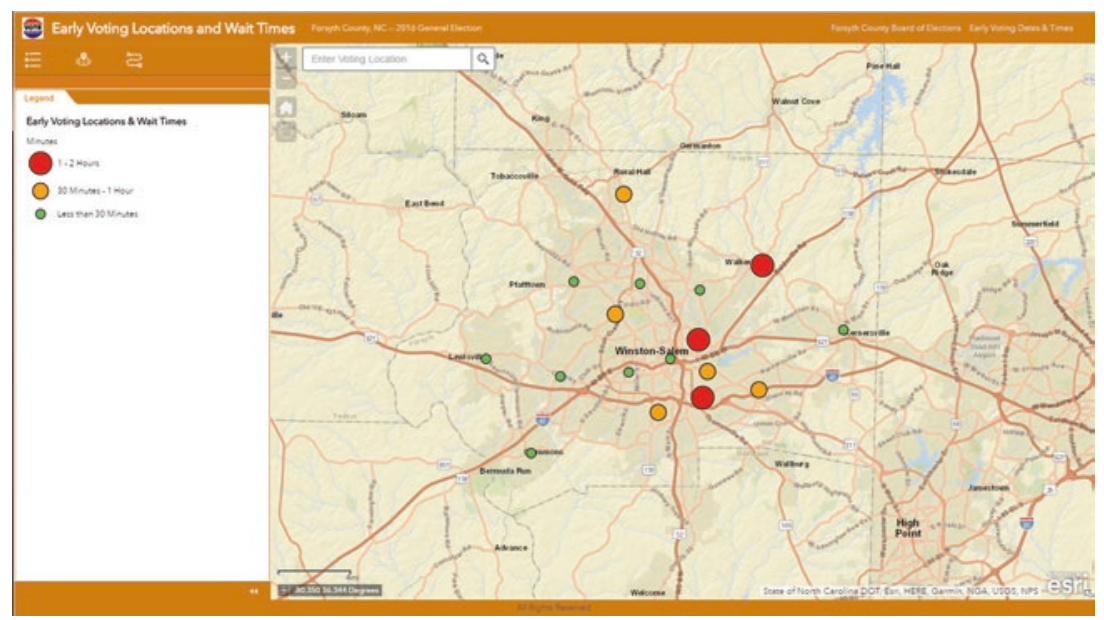

Fig. 22.4 Screenshot of EVWait Times

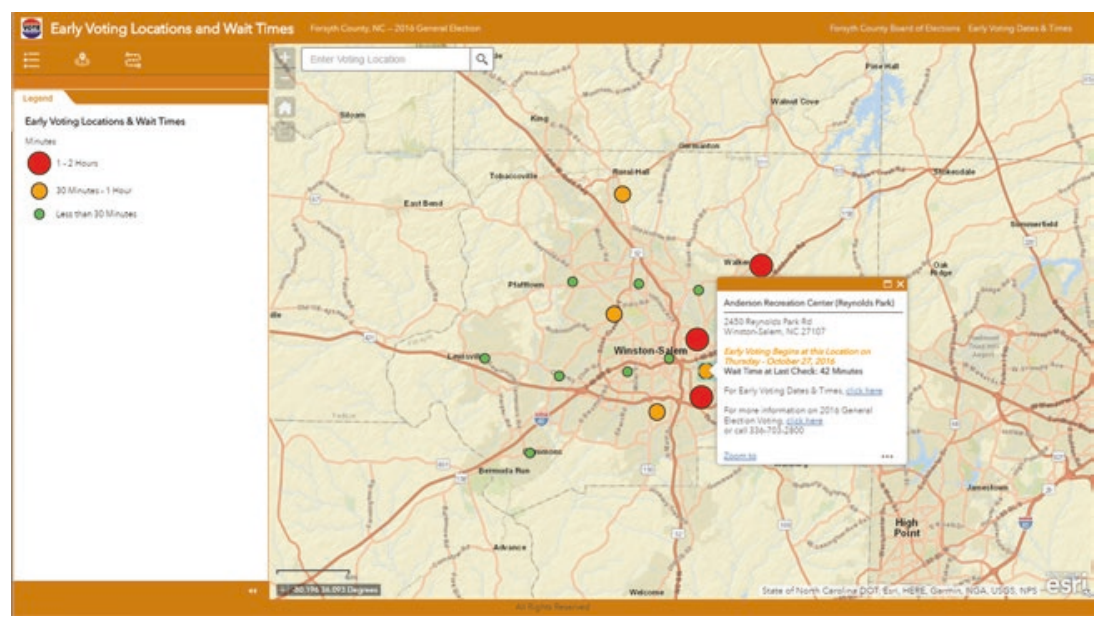

Fig. 22.5 Screenshot of EVWait Times with information pop-up 


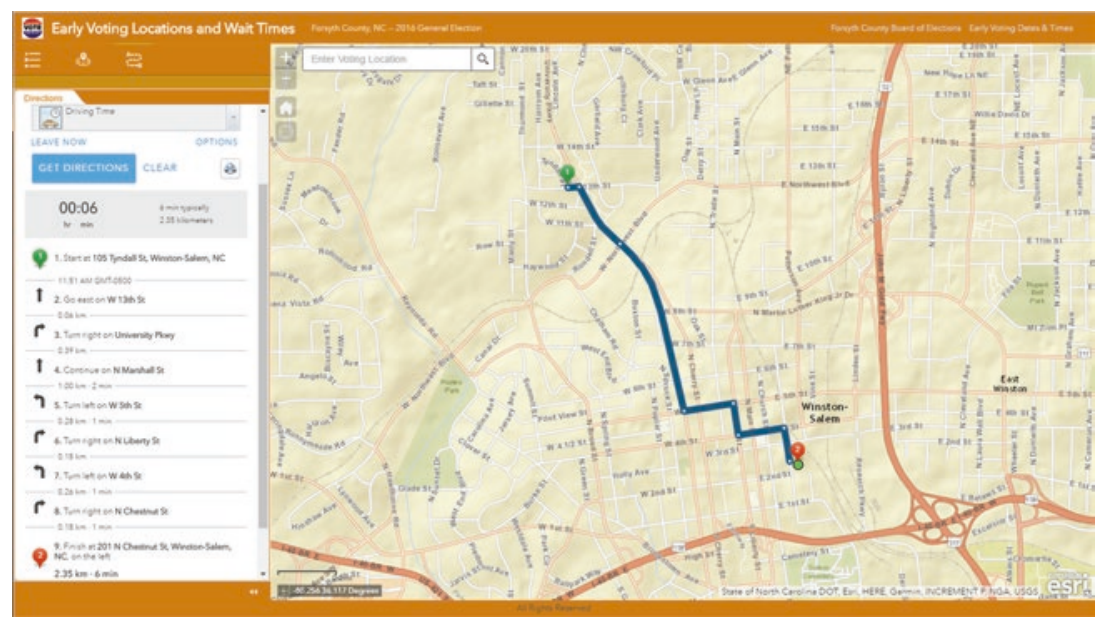

Fig. 22.6 Screenshot of EVWait driving directions

Another feature built into the EVWait Times is the ability to locate voting sites near your location (Fig. 22.7). An individual can either input their address or use the Locate Me button. Once the individual is located, the application drops a pin and displays a radius of 5 miles, returning a list of all early polling sites within the 5 -mile radius. The users can adjust the radius distance manually using the slider bar.

The Early Voting Wait Time Application (EVWait Times) was used during the early voting period of October 20, 2016, through November 5,2016 . Citizens, poll workers, and elected officials used the application for information purpose about wait times and polling locations. The application had a daily average of 3908 views per day with 62,530 views during the entire early voting period (Fig. 22.8 ), which is approximately $59 \%$ of the 105,334 total voters that cast their ballot during early voting. Figure 22.9 provides a snapshot of the daily average and total views during the 2018 general election.

In each iteration of the app we experienced limitations in WiFi connectivity. In 2016, there were several sites where the voting line extended beyond the voting enclosure. We were using mobile hotspots at those locations and the line manager had to take the iPad outside of the WiFi boundaries. We had to devise a plan during early voting to establish the 


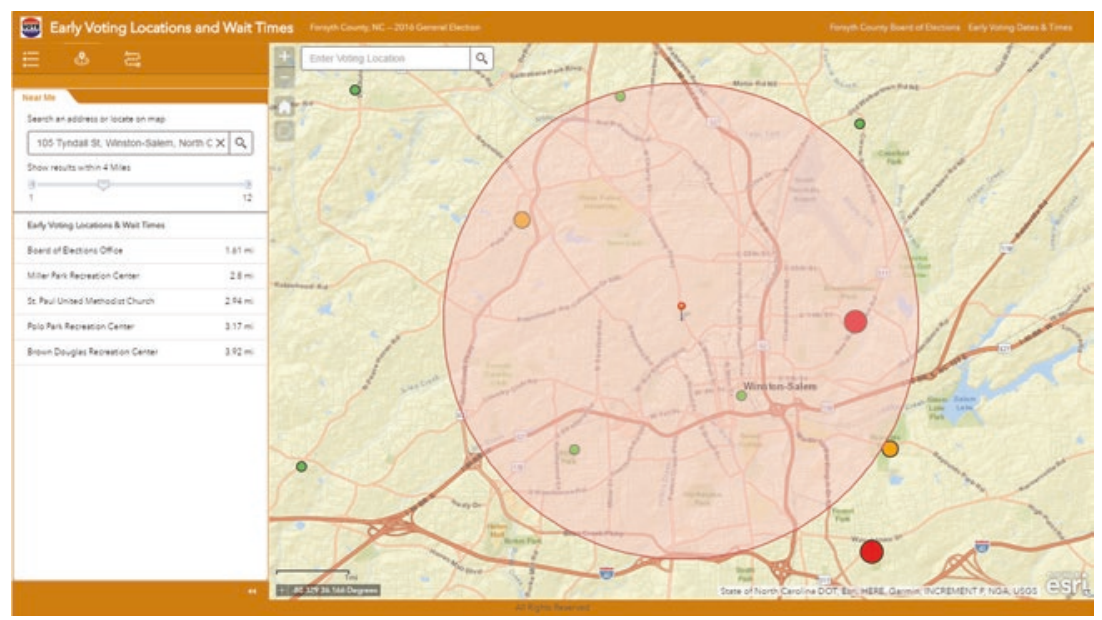

Fig. 22.7 Screenshot of EVWait Times locate nearest location feature

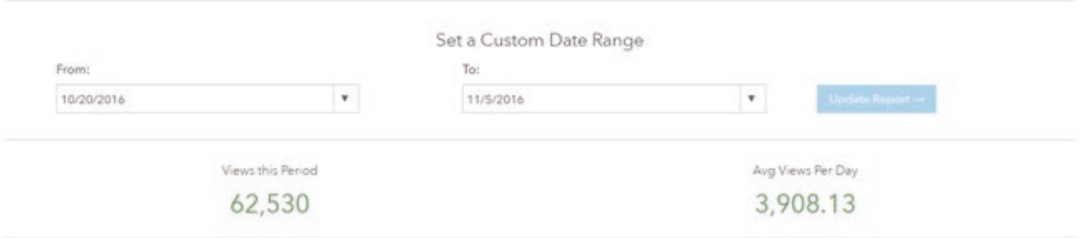

Usage Time Series

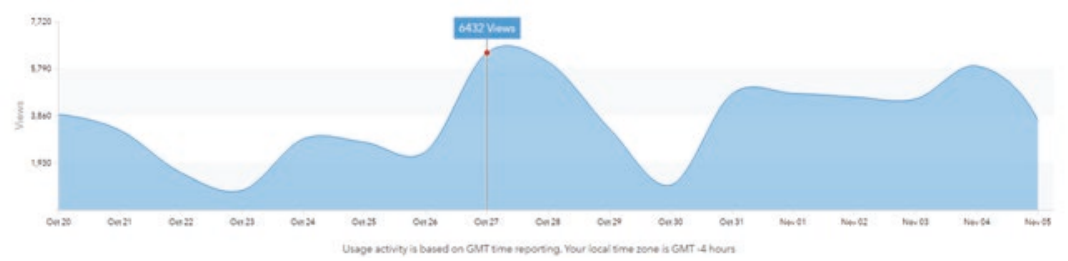

Fig. 22.8 AGOL screenshot of EVWait Times number of users during $10 / 20 / 2016-11 / 05 / 2016$

boundaries so that connectivity was constant. Poll workers were using the iPads for both line management and voter lookup to expedite any paperwork before the voters arrived at the registration table. Their offthe-cuff plan was to know where the boundary was and then position themselves in that spot so they could connect with the voter at that point. 


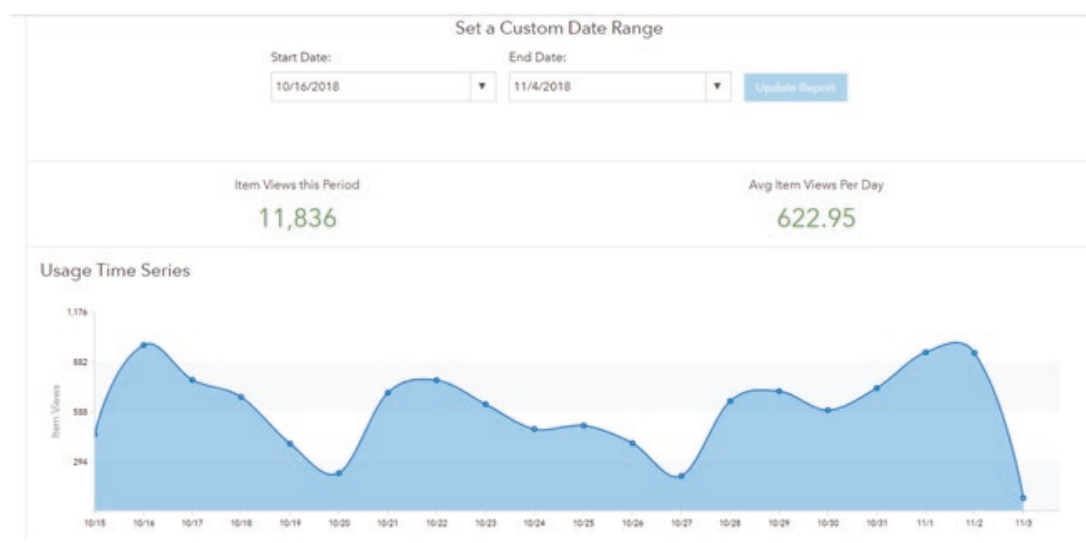

Fig. 22.9 AGOL screenshot of EVWait Times number of users during $10 / 16 / 2018-11 / 3 / 2018$

With the wait time app, they pushed the button inside the WiFi area and then took the card to where the voter was outside the line. We learned a great lesson about WiFi capability and improved on that.

The second challenge that we encountered was that some poll workers forgot to stop the stopwatch at the end of the day to reset the wait time on the website so it would show "less than 5 minutes." This meant that if a voter checked the wait time first thing in the morning, it would reflect the last wait time from the night before. The data uploaded into the database would be incorrect, which meant that we had to manually refresh the wait times. We also encountered challenges with resetting the wait times during the slow periods of each day. Through improved training we were able to resolve this for our last election.

The great thing about our tool is that it can be easily replicated. Several jurisdictions outside North Carolina have contacted me for the code and instructions to set it up for use in their jurisdictions. One jurisdiction in Colorado ran a pilot alongside us with our first iteration, and they found that it did not serve the wait time purposes for their county. However, it did provide information that helped them track poll worker hours in their county as they didn't have a mechanism to track poll worker hours during their early voting. Not only can it be easily replicated for free but the only cost would be for any WiFi-enabled devices, the cost of printing the cards, and the license for the ESRI tool. 
Ultimately, our goal was to find a way to quickly disseminate the wait time information to voters. The secondary benefit is to use the information that was collected during this time to analyze the early voting traffic and determine which sites received more early voters than others. This information will allow our staff to make any improvements for future elections to better manage the voter turnout at the early voting sites. Feedback from poll workers, voters, and the media has been very positive. Numerous news stories appeared in local and regional print and TV media that highlighted the app and its development.

\section{Other Technology Developments}

We are currently looking into virtual reality, or augmented reality, poll worker training. We are taking the concept of the Pokeman-Go augmented reality application and applying it to poll worker training. We believe that hands-on training is the best way to teach adults, but we cannot always do this. A tool like this will give us a readily available training tool that can be accessed on our website. A poll worker can click on the tool and see the voting machine and receive instructions about how to set it up, how to open and close the polls, how to sign in a voter, and so on. They can do this hands-on in a virtual polling place setting. I've purchased virtual reality glasses and we are testing different ways to use this. We hope to get this off the ground for use in the 2020 presidential elections.

There are always constant changes and new advances in technology. We are trying to keep up with this to benefit poll workers and voters for our county. We are also embracing them. These new apps have reinforced our belief in what technology can offer our election office and by extension our voters. 
Open Access This chapter is licensed under the terms of the Creative Commons Attribution 4.0 International License (http://creativecommons.org/licenses/ by $/ 4.0 /$ ), which permits use, sharing, adaptation, distribution and reproduction in any medium or format, as long as you give appropriate credit to the original author(s) and the source, provide a link to the Creative Commons licence and indicate if changes were made.

The images or other third party material in this chapter are included in the chapter's Creative Commons licence, unless indicated otherwise in a credit line to the material. If material is not included in the chapter's Creative Commons licence and your intended use is not permitted by statutory regulation or exceeds the permitted use, you will need to obtain permission directly from the copyright holder.

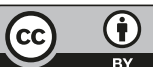

